\title{
36 \\ Greening the 2008 STLHE Conference: Sustainability as a Teaching and Learning Challenge
}

\author{
Lindita Prendi, Beverley Hamilton, \& Paul Henshaw \\ University of Windsor
}

Conferences are a great way to exchange ideas, communicate research findings, network, and more. However, as a teaching and learning community, we are becoming increasingly aware of the importance of environmental sustainability. The 2008 Society for Teaching and Learning in Higher Education conference organizers chose A World of Learning as its central theme, evoking the challenges and possibilities of internationalization and globalization in post-secondary settings and encouraging presenters to explore the impact of these trends in colleges and universities. As the conference program began to evolve, it became clear that the theme also represented an important opportunity to consider the ecological impact of this annual event. This paper examines the intent, outcomes, and implications of the initiative, illuminating the ways in which initiatives that, at first glance, appear logistical and material-based, are in fact better understood as changes in individual, community, departmental, and institutional values and practices. The potential of projects, such as this one, to function as cocurricular teaching and learning opportunities in promoting institutional change is also explored.

\section{Introduction}

rom the earliest planning stages, the organizers
of the 2008 Society for Teaching and Learning in Higher Education (STLHE) conference were determined to limit its environmental impact. The conference was, after all, focused on the theme $A$ World of Learning - it seemed to be the perfect opportunity to move towards sustainable practices on the wider scale, both for the conference and for the University of Windsor's campus. This paper charts the initiative's challenges and successes.

\section{A Heavy Footprint}

Conference-related travel, disposable dishware, handouts, conference giveaways, disposable food, beverage 
packaging, waste food from catered sources - the average conference-goer produces waste and consumes energy at a rate well beyond that individual's typical environmental 'footprint.' When researchers calculated the footprint of a smaller, two-day conference in Scotland, they determined that the energy use and waste production involved per capita was higher than the equitable 'earthshare' per person, per day (SDRC, 2006). Conference-goers generally use disposable materials, like dishware, which uses energy and natural resources at an exorbitant rate. The Environmental Defence Council, for example, argues that using 1,000 disposable plastic teaspoons consumes "over ten times more energy and natural resources than manufacturing one stainless steel teaspoon and washing it 1,000 times" (Desmond, 1998). David Suzuki noted that meetings "leave a heavy footprint on the environment" (Doyle, 2006).

When we began to develop a plan of action for greening the conference, we asked ourselves what the most environmentally friendly event we could run would be like. This frankly prompted the answer, "No conference at all." Yes, technologies such as videoconferencing, online synchronous and asynchronous discussion, teleconferencing, wikis, and virtual learning environments offer alternatives to the traditional faceto-face scholarly or professional conference, providing comparable opportunities for presentation, dissemination, and even networking. However, these media cannot replicate the interactions and outcomes of faceto-face conferences (Jones, 1995; McLaughline et al., 1995). Virtual environments continue to evolve in their capacity to represent shared spaces: constructing 15 simultaneous sites for groups of between two and 400 , providing comparable visual and interactive environments remains beyond reach. For most conference goers, the opportunity to meet face-to-face with old and new colleagues is an important, even indispensable, part of the event.

Although still a new area, the green conference movement has spawned a number of useful guides such as the Green Meeting Guide (Environment Canada, 2007), which provides clear and detailed information regarding the 'what' of conference greening. Still, there are many unknowns and challenges that conference organizers face when working toward the greening of an event. The navigation of the higher education institutions' setting was simply not something these guides covered, and overcoming these challenges can be seen as a learning opportunity.

\section{Conference as Microcosm: Greening as Curriculum}

For the past 27 years the STLHE conference has brought together educators, administrators, students, and staff to exchange ideas and share experiences related to teaching and learning in higher education. The 2008 conference theme, $A$ World of Learning, demanded greater awareness of the ecological impact of this annual conference, which in 2008, involved 475 participants from ten countries. The immediate goal, therefore, was to reduce the impact of the conference on the local environment. We also hoped to measure the impact of our efforts and to use this data and this pilot project to establish lasting changes in campus practices.

Greening a campus is logistical and curricular. Environmental pollution and resource management are not just technical fields: there are social, political, and ethical aspects to be considered, and integrating these diverse fields in a practice is challenging. Another approach is to alter curricula to infuse environmental principles into our course content and teaching practices. The challenge lies in how to integrate all these aspects into our curriculum to teach to our students, and in determining the scope of the curriculum: if students in an environmental engineering or law program explore the complexities of environmental practice in class, but emerge from their classes to face a campus that contradicts such values, to what degree does this divide shape their learning? Does it become an opportunity for cynicism, or for activism?

As we pursued our goal of greening the conference, we learned about the potential that such initiatives have as opportunities to test theoretical knowledge in real world contexts. Altering conference goers' habits and practices required knowledge of the culture and structure of the conference-attending community, the hosting organization, and avail- 
able local resources. Also, the important question of 'how much greening' needed constant reconsideration and reflection. The organizing committee hired an environmental coordinator, a doctoral student in environmental engineering, to take on the task of planning, implementing, and assessing the green initiative. She worked in collaboration with Centre for Teaching and Learning (CTL) staff to establish procedures and policies. This process served as an excellent learning opportunity for all, as her technical expertise acted as a strong balance to the knowledge of campus procedures and culture that CTL staff brought to the project. In this way, the project served as a useful case for determining the kinds of learning that a greening initiative of this type might have to offer. The next section will examine the intent, outcomes, and implications of the initiative.

\section{Summary of Green Conference Initiatives}

Figure 1 illustrates the Green Initiative vision statement and objectives, which emerged out of discussion with the organizing committee, the greening committee, and review of green conference literature.

\section{Minimize waste generation and energy use}

The following initiatives were undertaken for the conference in order to minimize waste generation and energy use:

- Biodegradable dishware and cutlery were used, made from renewable materials such as corn and sugar cane (bagasse). Comparable

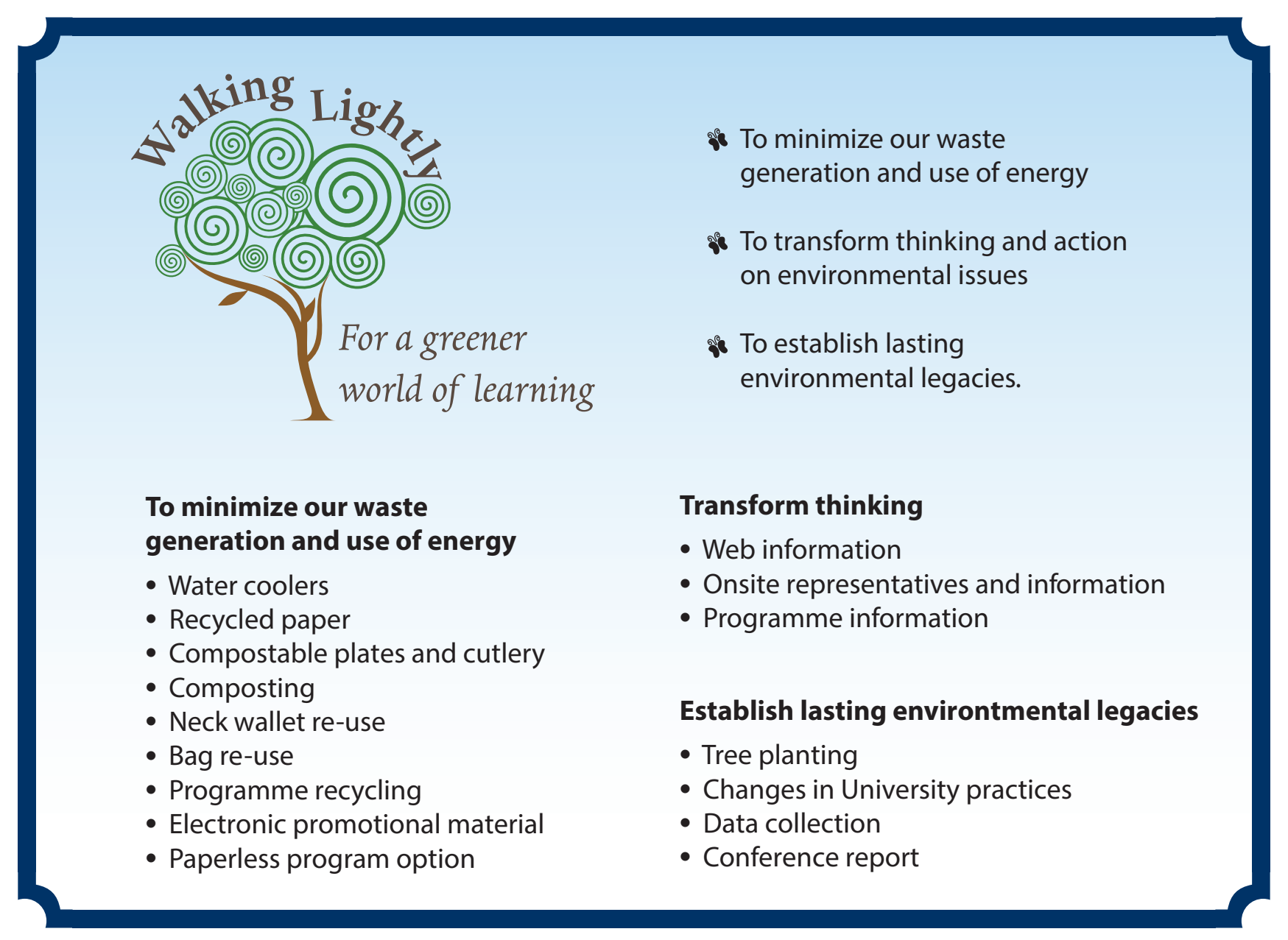

Figure 1:

Vision Statement and Objectives of the STLHE Green Initiative 
in cost to conventional products, the rising cost of petroleum-based products made these even more cost-effective (NatureWorks, 2008). Dishes were composted through the Windsor-Essex Waste Authority Composting Pilot Program: this also involved the use of biodegradable refuse bags throughout the conference.

- Water coolers were provided so that participants could use re-usable water bottles (conference give-away) rather than disposable individual containers.

- Where health rules allowed, condiments, etc. were served from large containers.

- During pre-registration, participants could select a paperless program option (conference materials on USB stick) and online personal scheduler (MySchedule). Hard copies of the program were printed on recycled paper, with the exception of the covers and dividers.

- Limits were placed on the use of hard-copy publicity.

- All documents were printed on recycled paper.

- Speakers were encouraged to reduce reliance on printed handouts.

- Recycling receptacles were available in all rooms, including composting receptacles.

- Program conference materials (bags, wallets, and notebooks), which were not used or which were returned, were donated to local community organizations, or collected for future use by the CTL and other University departments.

- Energy savings were implemented through room temperature moderation and turning off lights when not needed.

\section{Transforming thinking}

Many aspects of conference activity are habitual. We encouraged conference participants to choose environmentally friendly travel options through the conference website, and made bicycle rentals available. We offered a carpool sign up, and encouraged people to limit their own ecological impact while in Windsor through hotel and transportation selection. Many of these initiatives had limited uptake, but their use could increase with familiarity and repetition.

Dedicated greening volunteers were also onsite, gathering data from participants, ensuring that the initiatives ran smoothly, and answering participant questions. These volunteers were vital in ensuring that changed procedures were understood and in solving emerging problems. More volunteers would have helped with more complex aspects of the initiative, like composting.

\section{Establishing lasting legacies}

In an effort to offset future carbon dioxide emissions, the greening committee arranged for the donation of 25 trees to the university from the Essex Regional Conservation Authority (ERCA). The University's Ground and Environmental Services department has agreed to care for them until they are ready for planting. As well, the University donated a tree for immediate planting at the conference; this tree symbolized both the greening initiative, and the larger initiative of the growth and dissemination of knowledge.

Other legacies are less tangible, but no less significant. Data regarding the ecological impact of the conference, and the initiative's inclusion in the STLHE conference report, promote the integration of these practices into future conferences. On campus, individual departments, catering, and conference services have contacted the environmental coordinator to discuss the feasibility of green alternatives. Co-operation in the Windsor-Essex composting pilot program has increased campus awareness of options previously believed to be impossible.

\section{Learning from Challenges}

Studies of environmental psychology indicate that, although people are generally aware of environmental problems ranging from local to global issues (McKenzie-Mohr as cited in Berenguer, 2007), responsible environmental behaviour is not the norm. Christensen (2007) suggests identifying minimum best-practice options, and low- or no-cost measures that can be 
readily implemented with strong return on investment. In general, the most easily implemented measures were those that were not considered out of the ordinary and had little effect on the operation of the conference or participant behavior, such as the use of recycled paper, recycling boxes for unused programs, electronic promotion material and information dissemination, and electronic registration.

The committee often discussed potential 'push-back' from participants frustrated by changes to standard conference practices and resource limitations. Determining reasonable changes was often a challenging process, requiring creative problem solving from everyone. The committee determined what could be reduced, reused, or recycled - the three goals arranged in declining order from most to least optimal. For example, when a sponsor's donation of conference material precluded the purchase of bags made entirely from organic or recycled materials, the committee established a re-use program to collect and donate the materials to a local organization that supports the professional integration of new Canadians.

Another aspect involved the complexity of effecting change in institutional practices. For example, the committee initially advocated for china service, but Catering Services argued that china service for 500 was not feasible, and instead proposed corn and bagasse-based plastic plates. These options had previously been examined, but were dismissed due to relative energy use, the potential for allergens, and the difficulty of composting the dishes, which would require biodegradable bags and an elevated temperature composting facility. The Windsor-Essex composting pilot was then found to accept and properly compost the material. This compromise demanded research and involvement from catering, conference services, janitorial staff, and those responsible for University waste removal. The number of departments involved can be found in Table 1 and the decision-making process is delineated in Figure 2. A further element of this educational process involved ensuring that conference participants learned to use the composting bins properly (dishware and some food could be recycled, but not meat). Dishware items were taped to organic waste bins to identify them as being compostable, posters were displayed, and volunteers were

\section{Table 1}

\section{Departments and Organizations Involved with the Composting Initiative}

\begin{tabular}{|l|l|}
\hline Departments at the University & Outside the University \\
\hline Grounds-Environmental Services Department & ERCA \\
\hline Conference Services & Forestry Department of the City of Windsor \\
\hline $\begin{array}{l}\text { Custodial Services-Environmental Services } \\
\text { Department }\end{array}$ & Essex-Windsor Solid Waste Authority (EWSWA) \\
\hline Energy Conversion Centre & Walmart \\
\hline Catering Services & Canadian Tire \\
\hline $\begin{array}{l}\text { Great Lakes Institute of Environmental Research } \\
\text { (GLIER) }\end{array}$ & Radisson and Hilton Hotels \\
\hline University Advancement & Parks and Recreation Department (City of Windsor) \\
\hline Finance & Courtesy Bicycles \\
\hline Volunteer Internship Program & TD Friends of the Environment Fund \\
\hline Environmental Engineering Programs & \\
\hline Alumni Hall (residence)
\end{tabular}



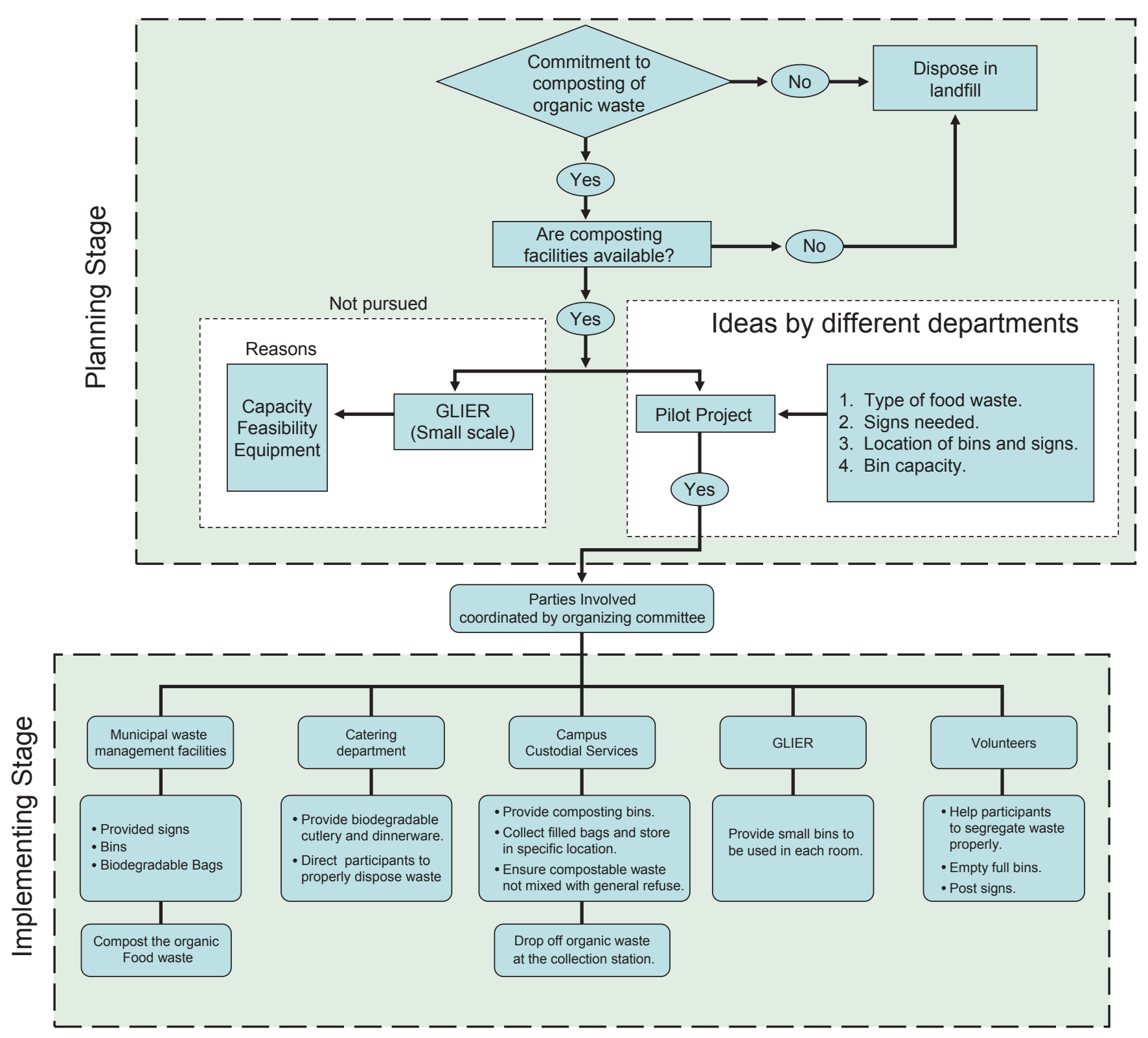

Figure 2

Decision-Making Process for Composting of Organic Food Waste

available for help. Still, some items were disposed as regular garbage. Clearly, dissemination of information is essential.

\section{Challenges: The Learning Opportunity}

As the previous section will attest, there are ample opportunities for growth, reflection, and skill development involved in working to establish even one element of such an initiative. The composting processes, for example, provided opportunities to hone communications and collaborative skills, employ and develop research and critical thinking skills, and expand technical expertise in the requirements and methods of composting. At every stage, the cycle of collaboration served as a real-time setting for reflec- 
tive thought and critical evaluation of ethical and logistical dilemmas. The project required creative problem solving and a resilient approach to overcoming barriers. A key to successfully incorporating this kind of initiative into more formal curricula would be to identify skills to be developed and assessed. The CTL staff and the greening committee were, at times, surprised by unexpected setbacks and unexpected support, and while diplomacy and flexibility were two characteristics of this project, repeated involvement in similar projects would have helped predict challenges.

\section{Participant Feedback: One Measure of Success}

Compiled data from conference evaluations indicated that $78 \%$ of respondents were very pleased with the greening measures and felt that the initiative enhanced their conference enjoyment.

Comments like "please continue in future STLHE conferences" and "great job" were very encouraging. While some appreciated the greening initiative's consistency with their typical practice, others saw it as something different - they were not "used to it," but were eager to do their share to lessen the environmental burden while attending conferences like this one. Figure 3 summarizes evaluation responses to the green initiative. A limited number indicated strong disagreement with the environmental initiative, commenting, for example, that they found it "obnoxious" and "overdone." Similarly, responses to specific aspects of the greening initiative indicated varied awareness of the complexities of greening:

- Some participants felt that the USB sticks and personal scheduler were much less practical than envisioned, others found them effective, and still others felt that they might work effectively combined with hardcopy daily summaries and centralized printing stations. Some also questioned whether the re-usable USB stick was more environmentally friendly than hard copy programs. Participants held strong but diverse views regarding these initiatives. Technological initiatives involving the ways people organize their learning plans and accessed information about the conference required more pre-conference communication explanation. Highly visible technical support would have been of benefit.

- While some participants indicated that they would be taking the idea of biodegradable dishware back to their campuses, others felt that the corn-based dishware used resources that could be put to better use feeding people, rather than being embodied in single-use products. Participants noted that the biodegradable cups, used for coffee, softened and leaked over time. More product testing would have been of benefit.

- Some participants questioned whether certain green choices were truly 'green,' for example, whether the 'compost' was truly composted, and in what way? Some questioned the effectiveness of a carbon offset option, a somewhat controversial practice in environmental circles. Critics argue that carbon offsets do not reduce the problem of climate change, and further, some programs are more legitimate than others in this regard. Although carbon offset is a popular approach to neutralize environmental impact, choosing projects that fulfill the most recognized standards and criteria is imperative.

Conference-goers' responses to the initiative truly reflected the range of opinions typical of any complex social issue involving changing behaviours. Interest in, and critical awareness of, environmental practice varies, making it difficult to develop plans that satisfy all parties involved. For the majority, it appeared to have struck the right balance. With each future conference, it will be possible to shift the parameters of what is considered 'normal practice' in the direction of greater sustainability.

Prioritizing initiatives is not a simple process. It involves identifying: potential areas for change; parties involved; barriers to the change; sources for 


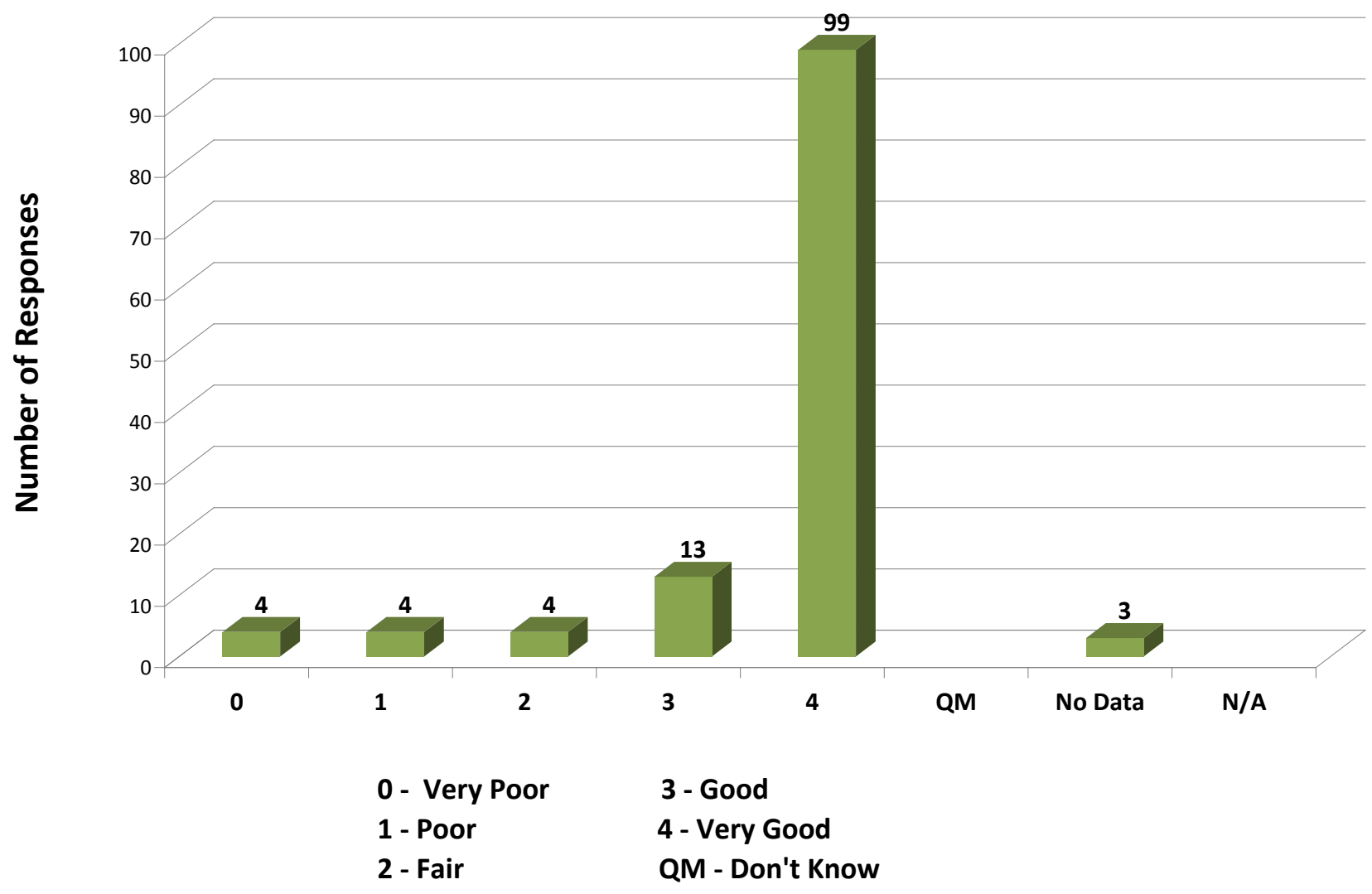

Figure 3

Degree to which the Greening Initiative Affected Participants' Enjoyment

materials and services; and negotiation of groups with varying commitments to the initiative. While Christensen (2007) suggests implementing wholesale change as the most efficient way to adopt environmentally sustainable conference practices, this was not our experience on a university campus where essentially independent departments provide event support. Conference feedback did not indicate that this would have been a preferable approach.

In retrospect, the extremely diverse voices involved in the planning process predicted likely points of tension for conference-goers as well. Members of the organizing committee felt that an entirely paperless or a half-size program would be too frustrating for many participants. The greening committee then proposed alternatives such as the choice of an electronic version, the use of $100 \%$ post-consumer paper, and the opportunity to recycle.

Inevitably, some decisions made in this con- text were not those others would make. Although these decisions were explained in the conference documentation, feedback indicated that more information and varied avenues of communication would have been of benefit. A conference presentation dedicated to the green initiative was poorly attended due, in part, to the competition of excellent simultaneous presentations. In spite of this, more varied and sustained communication would certainly improve the chances of uptake and satisfaction. The greening committee learnt that change is, at its core, a process of communication, of clarifying options, creating community, identifying values, and explaining practices. As a learning process, such projects offer profoundly valuable opportunities to reflect upon the social nature of sustainability, and the complex variety of values and practices typical of all communities. This project prompted a critically reflective stance, primarily through the ongoing negotiations 
between all parties involved to make it a success, requiring constant willingness to consider others' perspectives, needs, and resources.

Greening initiatives should be understood as a full program of integrated activities. To effect lasting change in institutional practice, departments need ongoing support. In the past few years, many universities have embraced environmentally sustainable projects and operations. In most cases, these projects have been isolated from the rest of the institution's activities. Often, sustainable initiatives go unnoticed and their impact is low (Hailey, 2008). Hailey suggests that "the next step is to go beyond these often separate and isolated projects to incorporate a systemic and integrated approach that sees sustainability become integrated into all the functions of a university." A conference can be an impetus to change, but discrete elements of a larger initiative adopted without integrated support have limited impact. Replacing disposable cups with biodegradable ones changes the resulting waste very little unless implemented with a composting program using biodegradable bags. Such an initiative, therefore, requires ongoing interdepartmental co-operation on the establishment of waste streams. Integration of these more holistic objectives into formal curricula could be mutually beneficial.

\section{Conclusions}

The decision to embark on an initiative such as greening involves subtle and reflective reading of the existing culture, its potential for change, available resources, conflicts between conference-goers' needs and practices, and the changes initiated. While assessing available options requires technical expertise, true and lasting change emerges primarily through working with others, understanding how organizations function, and how communities and individuals work. Likewise, student and staff learning emerged in this case from the process of working through technical options in a diverse social and institutional context. For the greening committee, communication processes surfaced as a key growth area, requiring patience and reflection, multiple av- enues, long-term planning, foreseeing challenges and frustrations, and real-time maneuverability during the conference itself. The lessons learned from this project will add to the reserve of knowledge augmenting our institution's environmental pinnacle in its ongoing effort to establish and understand the interactions between learning, logistics, and practice in campus sustainability initiatives.

\section{References}

Berenguer, J. (2007). The effect of empathy in pro-environmental attitudes and behaviors. environmental behavior, 39(2).

Christensen, I. (2007). Southeast regional environmental finance centre. University of Louisville, Center for Environmental Policy and Management, Louisville, KY.

Desmond, R. (1998). An ounce of prevention: Think ahead before you buy. Retrieved from the Environmental Defense Fund Website: http:// www.sdearthtimes.com/et0798/ et0798s12. html

Doyle, A. (2006). David Suzuki: We have to be the change we want. PCMA Bulletin, 70-75.

Environment Canada's green meeting guide. Retrieved October, 2007 from http://www.greeninggovernment.gc.ca/F5B1C0BC-741C-4493B4B7-B0D56BBE6566 /Green_Meeting_ Guide_07.pdf

Hailey, K. (2008). Building a sustainable institution. University Manager.

Jones, S.G. (1997). The Internet and its social landscape. In S.G. Jones (Ed.), Virtual culture: Identity and communication in cybersociety (pp. 7-35), Thousand Oaks: SAGE.

McLaughlin, M.L., Osborne, K., \& Smith, C.B. (1995). Standards of conduct on Usenet. In 
S.G. Jones (Ed.) Cybersociety: Computer mediated communication and community (pp.90111). Thousand Oaks CA: SAGE Publications.

Sustainable development research centre [SDRC]. (2006). The ecological footprint of a conference in the Scottish Parliament, Forres, Scotland. Retrieved December, 2007, from the Sustainable Development Commission Website: http://www.scottish. parliament.uk/business/ research/briefings-06/EcoFoot.pdf

Zentner, A. \& Lieb, A. (2008). Lifecycle analysis for Piazanos packaging alternatives. Retrieved January, 2008, from http://envs.colorado. edu/uploads/undergrad/Llifecycles_Plastics,_ PLA,_Aluminum.pdf

\section{Biographies}

Lindita Prendi is a doctoral candidate in the Department of Civil and Environmental Engineering at the University of Windsor, Ontario. Her research includes the investigation of parameters affecting aesthetic and protective properties of automotive coatings, Life Cycle Analysis of automotive paint processes, and ecological footprint of events. She has taught many courses at the university and college level and participates in workshops and other events related to teaching and learning in higher education.

Beverley Hamilton is the Assistant to the Vice-Provost, Teaching and Learning at the University of Windsor, Ontario. Her pedagogical research interests include the use of metaphor as a tool for reflective practice, the role of narrative identity in teaching and learning, and collaborative approaches to institutional change.

Paul Henshaw is an Associate Professor in the Department of Environmental Engineering at the University of Windsor, Ontario. His research interests include automotive coatings, wastewater treatment, and solar thermal energy systems. 